\title{
Surveillance of antimicrobial resistance of maltose negative Staphylococcus aureus in South African dairy herds
}

Joanne Karzis ( $\nabla$ joanne.karzis@up.ac.za )

University of Pretoria https://orcid.org/0000-0002-6210-0985

Inge-Marié Petzer

University of Pretoria

Edward F. Donkin

University of Pretoria

Vinny Naidoo

University of Pretoria

Eric M. C. Etter

CIRAD

Research article

Keywords: Antimicrobial resistance, Staphylococcus aureus, mastitis, somatic cell count, seasons, regions, MIC

Posted Date: April 29th, 2020

DOI: https://doi.org/10.21203/rs.2.18013/v2

License: (c) (1) This work is licensed under a Creative Commons Attribution 4.0 International License.

Read Full License 


\section{Abstract}

Background The discovery of antimicrobials in the 1930s was one of the greatest achievements in medicine. However, bacterial resistance to antimicrobials was already observed in the 1940s and has been reported since then in both human and veterinary medicine, including in dairy cows. Many years of monitoring milk samples in South Africa, has led to the identification of a new strain of Staphylococcus aureus (S. aureus), which is maltose negative and appears to be an emerging pathogen. In this study the differences in susceptibility to antimicrobials of this strain were evaluated over time, over different seasons, in different provinces, and according to somatic cell count (SCC) categories.

Results A data set of 271 maltose negative S. aureus isolates, cultured from milk samples from 117 herds out of the estimated 2000 commercial dairy herds in South Africa between 2010 and 2017, was studied using the disk diffusion method. This analysis was done using the Clinical Laboratory Standards Institute (CLSI) breakpoints in order to compare using both the previous (Intermediate category grouped with Resistant) and current definitions, (Intermediate category grouped with Susceptible). The results of the analysis between the previous and the current definitions differed for tylosin, cefalonium, oxytetracycline and cloxacillin. Neither the analysis using the previous nor the current systems showed an effect of province for the maltose negative $S$. aureus. This was in contrast to the results for maltose positive S. aureus where differences between provinces were shown in a previous study, with the lowest prevalence of resistance shown in KwaZulu-Natal during spring. For the susceptibility testing of 57 maltose negative and 57 maltose positive $\mathrm{S}$. aureus isolates from 38 farms, from KwaZulu Natal, Eastern Cape and Western Cape. The minimum inhibitory concentration (MIC) results for the maltose negative S. aureus isolates confirmed the results of the disk diffusion method.

Conclusions The maltose negative strains of S. aureus differed in general, in their antimicrobial resistance patterns over time, in comparison to maltose-positive $S$. aureus strains. MIC testing also indicated that more multidrug -resistant isolates were seen with the maltose negative $\mathrm{S}$. aureus than in the maltose positive strains.

\section{Background}

The genus Staphylococcus consists of a variety of opportunistic pathogens of variable relevance in veterinary medicine. The most clinically relevant staphylococci in veterinary medicine are the coagulase positive Staphylococcus aureus [37], members of the S. intermedius group [32], as well as the non-aureus staphylococci [26]. A noted property of staphylococci is their ability to develop resistance to antimicrobials (e.g.by mutations). Methicillin resistance is of particular relevance, because it is conferred by a presence of the mecA gene, which encodes for the production of an altered penicillin binding protein (PBP) (PBP2a or PBP2) that has a low affinity for the beta-lactam antimicrobials (penicillins, older cephalosporins, carbapenems) [19]. Methicillin-resistant $S$. aureus (MRSA) is recognised as a significant problem in human medicine and it is among the most important infections in hospitalized individuals and in people in general [18]. 
In South Africa S. aureus (maltose positive) still remains a challenge to udder health [27], although this has been reported to no longer be the main challenge to udder health in all countries [41]. Mastitis caused by $S$. aureus is still an issue in South Africa because it cannot be cured and it results in a high proportion of affected cows being culled, which has an important economic effect.

The infected udder is considered the primary reservoir of $S$. aureus and the organism is believed to be transmitted during milking. Despite this, a proportion of heifers which are already infected with $S$. aureus, enter the milking herd [25]. This suggests routes of transmission in addition to the milking equipment and the milking parlour. A good understanding of $S$. aureus reservoirs and transmission is essential for the effective control of the organism in a herd. The expectation of treatment resulting in cure of $S$. aureus (maltose positive) infection can be estimated by taking the following factors into account: parity; the stage of lactation; the SCC level; the specific teat position on the udder; the number of quarters infected; and the duration of treatment required [35].

The Milk Laboratory at the Faculty of Veterinary Science at the University of Pretoria has provided an extensive dairy cow udder monitoring programme in South Africa. Since 2005, an increasing number of coagulase positive, maltose negative staphylococci have been isolated, that were confirmed as maltose negative $S$. aureus by MALDI-TOF and 16 S rRNA sequencing methods [17]. These organisms were first identified from a dairy cow in a single South African dairy herd with an average individual somatic cell count of less than $100000 \mathrm{cell} / \mathrm{ml}$ of milk. Three years later similar organisms were isolated from numerous dairy herds in South Africa, albeit with effective susceptibility to antimicrobials that were tested routinely, with a low SCC [14]. These organisms did not appear to cause the same level of udder damage as maltose positive $S$. aureus and have not been found to cause any chronic or repeat cases in South Africa [14]. However in more recent years 2016/2017/2018, individual coagulase positive and maltose negative staphylococci showed resistance (MRSA, cefoxitin disk) and an increase in SCC of infected udders (> $400000 \mathrm{cells} / \mathrm{ml}$ milk) [14]. There is little information known about maltose negative $S$. aureus from dairy cows. A study in the Netherlands has also isolated a maltose negative strain of $S$. aureus [12]. However the strain found in the Netherlands [12] was different to that investigated in this study in South Africa. In addition to the previous study [17] which attempted to characterise this emerging pathogen, a further evaluation was carried out of the resistance trends evident in historic disk diffusion susceptibility data and more recent MIC data.

The main objective of this study was to investigate the retrospective (disk diffusion) antimicrobial surveillance data of unique maltose negative $S$. aureus ST 2992 in different provinces, seasons and SCC categories (using both previous and recent $S, I$ I R definitions) and to compare the MIC results of the maltose negative $S$. aureus that was previously identified as an emerging pathogen [17], to those of maltose positive $S$. aureus. Since this was a retrospective study, the study period crossed over various guidelines and definitions which could complicate the analysis.

During the 8 year period of this study, the CLSI M31-A3 method was replaced by the VET01-04 (2013) [8]. The latest breakpoints were used (CLSI) at the time of the study, for the retrospective disk method data [7; 
8].

However, while the breakpoints have not changed, the definition of Susceptible, Intermediate and Resistant have changed [13] which has affected the interpretation of the results mostly in the case of surveillance data. According to the previous definition, Intermediate results were combined with Resistant results or left as a separate uncertain category (yielding a stricter analysis). However, in the more recent definition, in times of increased resistance, the term Intermediate is defined as Susceptible with increased exposure. Thus in this situation for the purpose of data analysis Intermediate and Susceptible results are combined [13]. This is then useful in practice as Intermediate results can be used to select treatment products in cases where no products are available according to Susceptible results (e.g. for intramammary remedies). As a result the analysis was evaluated using both systems, in order to determine if the change in data classification analysis had an impact on the results. All previous studies were done using the previous definitions, and thus the results of this study could still be directly compared to those of other similar studies done in the past and be of value for comparison by other authors using the newer definitions.

The breakpoints are not just an indication of resistance. It takes into account concentrations at the level of the udder (i.e. its pharmacological resistance). In South Africa we have a limited variety of intramammary products available for use, mostly ampicillin, cloxacillin or combinations thereof. The products with available breakpoints for mastitis specifically, in the latest CLSI guidelines, are not available for use on the South African market. Thus, we used available CLSI veterinary breakpoints [8] and for the products on the MIC PM 32 panel with no available veterinary breakpoints, we used the CLSI human breakpoints [7], as explained and used in the publication by explaining the development of veterinary antimicrobial susceptibility guidelines over time [38].

\section{Results}

The first part of this study was the retrospective data analysis (disk diffusion) which was done only on maltose negative $S$. aureus, that combined the Resistant and Intermediate results and reported Susceptible results separately. The eight antimicrobials that were used in this retrospective study were the commonly used antimicrobials available as intramammary remedies in South Africa. The original definitions and the more recent definitions (Intermediate grouped with Susceptible) [13] of antimicrobial resistance showed similar trends. These trends of resistance to penicillin G, ampicillin, cephalexin, cefalonium, cloxacillin and oxy-tetracycline peaked (at highest) in 2011, and for tylosin in 2013, and then decreased over time. Nevertheless due to scarcity of data for the years 2009, 2010 and 2011 with respectively 4, 8 and 4 isolates, Figures 1, 2, 3, 4, 5 \& 6 did not show these years 
as confidence intervals would be meaningless. However, in 2017 there was a slight increase in antimicrobial resistance to ampicillin, cloxacillin, penicillin $\mathrm{G}$ and tylosin but not for cephalexin (Figures 1, 2, 3, 4, $5 \& 6$ ). The results of the GLMM confirmed that time (years) was a significant variable for antimicrobial resistance of maltose negative $S$. aureus to, penicillin G, ampicillin, cefalonium, oxy-tetracycline and cephalexin. According to the GLMM analysis, SCC category is the only significant variable for antimicrobial resistance to cloxacillin (Table 1). SCC category was also significant for the resistance to cefalonium. Season was a significant variable for penicillin G, ampicillin and cephalexin with spring being the season with the lowest level of resistance compared to autumn and to summer for the two first one whereas autumn was the season with the lowest level of resistance compared to summer for cephalexin.

These data were re-evaluated according to the more recent definitions [13] that grouped results from Susceptible and Intermediate data together, so that the Resistant data were reported separately. Some differences from the previous analysis were apparent as a detailed examination of Tables 1 and 2 will show. Using the latest definitions [13], the significant effects of year, season, province and SCC category disappeared on antimicrobial resistance of tylosin, cloxacillin, oxy-tetracycline and cefalonium (Table $1 \& 2$ ). Penicillin G, ampicillin and cephalexin showed similar effects of year and season for both the previous (Table 1) and the more recent definitions (Table 2). For ampicillin and cephalexin, the highest level of resistance is present during the same seasons (autumn and summer), the season showing the lowest level of resistance differed when comparing the two classifications (Table $1 \& 2$ ). Resistance to oxytetracycline and cefoxitin exhibited differences according to the SCC categories with the new classification. There was no effect of province on antimicrobial resistance when using both the previous (Table 1) and the more recent definitions (Table 2).

Table 1 Summary of variables effect on antimicrobial resistance (GLMM) according to [8], previous definitions [13]. 


\begin{tabular}{|c|c|c|c|c|}
\hline Antimicrobial & Year & Season & Province & SCC Category \\
\hline Tylosin & $\begin{array}{l}\mathrm{P}< \\
0.001\end{array}$ & NS & NS & NS \\
\hline Penicillin G & $\begin{array}{l}\mathrm{P}= \\
0.018\end{array}$ & $\begin{array}{l}\mathrm{P}=0.05 \\
\text { [Autumn } \mathrm{P}=0.03 \& \text { Summer } \mathrm{P}= \\
0.01] \text { vs. Spring (Lowest } \mathrm{R})\end{array}$ & NS & NS \\
\hline Ampicillin & $\begin{array}{l}\mathrm{P}= \\
0.005\end{array}$ & $\begin{array}{l}\mathrm{P}=0.025 \\
\text { [Autumn } \mathrm{P}=0.01 \& \text { Summer } \mathrm{P}= \\
0.01] \text { vs. Spring (Lowest R) }\end{array}$ & NS & NS \\
\hline Clindamycin & $\mathrm{N} / \mathrm{A}$ & N/A & N/A & $\mathrm{N} / \mathrm{A}$ \\
\hline Cefuroxime & NS & NS & NS & NS \\
\hline $\begin{array}{l}\text { Cefalonium } \\
\text { (2011-2017) }\end{array}$ & $\begin{array}{l}\mathrm{P}= \\
0.07 *\end{array}$ & NS & NS & $\begin{array}{l}\mathrm{P}=0.015 \\
{[\text { High SCC P }=0.01]} \\
\text { vs. Med SCC (Lowest } \\
\text { R) }\end{array}$ \\
\hline $\begin{array}{l}\text { Cefoxitin } \\
(2014-2017)\end{array}$ & NS & NS & NS & NS \\
\hline $\begin{array}{l}\text { Oxy- } \\
\text { tetracycline }\end{array}$ & $\begin{array}{l}\mathrm{P}< \\
0.001\end{array}$ & NS & NS & NS \\
\hline Cephalexin & $\begin{array}{l}P= \\
0.012\end{array}$ & $\begin{array}{l}P=0.05 \\
{[P=0.01 \text { Summer }] \text { vs. }} \\
\text { Autumn(Lowest } \mathrm{R})\end{array}$ & NS & NS \\
\hline Cloxacillin & NS & NS & NS & $\begin{array}{l}\mathrm{P}=0.024 \\
{[\text { Low SCC } \mathrm{P}=0.008]} \\
\text { Vs. High SCC (Lowest } \\
\mathrm{R} \text { ) }\end{array}$ \\
\hline
\end{tabular}

See text for detailed explanation

*Almost significant $\mathrm{P}>0.1, \mathrm{NS}=$ Not Significant, $\mathrm{R}=$ Resistance, N/A $=$ Not applicable

Table 2 Summary of variables effect on antimicrobial resistance (GLMM) according to [8], more recent definitions [13]. 


\begin{tabular}{|c|c|c|c|c|}
\hline Antimicrobial & Year & Season & Province & SCC Category \\
\hline Tylosin & NS & NS & NS & NS \\
\hline Penicillin G & $\begin{array}{l}\mathrm{P}= \\
0.06 *\end{array}$ & $\begin{array}{l}\mathrm{P}<0.001 \\
{[\text { Autumn } \mathrm{P}=0.001 \text { \& Summer } \mathrm{P}} \\
=0.002] \text { vs. Spring (Lowest } \mathrm{R})\end{array}$ & NS & NS \\
\hline Ampicillin & $\begin{array}{l}\mathrm{P}= \\
0.026\end{array}$ & $\begin{array}{l}\mathrm{P}<0.001 \\
{[\text { Autumn } \mathrm{P}<0.001 \& \text { Summer } \mathrm{P}} \\
=0.042] \text { vs. Winter (Lowest R) }\end{array}$ & NS & NS \\
\hline Clindamycin & N/A & $\mathrm{N} / \mathrm{A}$ & N/A & $\mathrm{N} / \mathrm{A}$ \\
\hline Cefuroxime & NS & NS & NS & NS \\
\hline $\begin{array}{l}\text { Cefalonium } \\
\text { (2011-2017) }\end{array}$ & NS & NS & NS & NS \\
\hline $\begin{array}{l}\text { Cefoxitin } \\
(2014-2017)\end{array}$ & NS & $\mathrm{P}=0.027$ & NS & $\mathrm{P}=0.018$ \\
\hline $\begin{array}{l}\text { Oxy- } \\
\text { tetracycline }\end{array}$ & NS & NS & NS & $\begin{array}{l}\mathrm{P}=0.09 * \\
\text { [Low SCC } \mathrm{P}= \\
0.098 \text { ] vs. High SCC } \\
(\text { Lower R) }\end{array}$ \\
\hline Cephalexin & $\begin{array}{l}\mathrm{P}= \\
0.01\end{array}$ & $\begin{array}{l}\mathrm{P}=0.02 \\
[\text { Summer } \mathrm{P}=0.012 \text { (Highest } \mathrm{R})] \\
\text { Vs. Winter (Lowest R) }\end{array}$ & NS & NS \\
\hline Cloxacillin & NS & NS & NS & NS \\
\hline
\end{tabular}

See text for detailed explanation

*Almost significant $\mathrm{P}<0.1, \mathrm{NS}=$ Not Significant, $\mathrm{R}=$ Resistance, N/A = Not applicable

Antimicrobial products shown in Table 3 are all the products from the PM 32 panel (Beckman Coulter) that showed Resistance to any of the isolates tested. The 57 maltose positive and the 57 maltose negative $S$. aureus isolates were all resistant to ampicillin. Out of the total of 114 isolates overall, only 37 were resistant to more than one product, 30 maltose negative $S$. aureus and seven maltose positive $S$. aureus. There were a total of 25 multidrug resistant (MDR) isolates (isolates resistant to an antimicrobial from three or more antimicrobial categories) [22], 3 maltose positive and 22 maltose negative $S$. aureus. 
Table 3 Minimum inhibitory concentrations (MIC) 90 and MIC 50 for maltose positive and maltose negative $S$. aureus. 


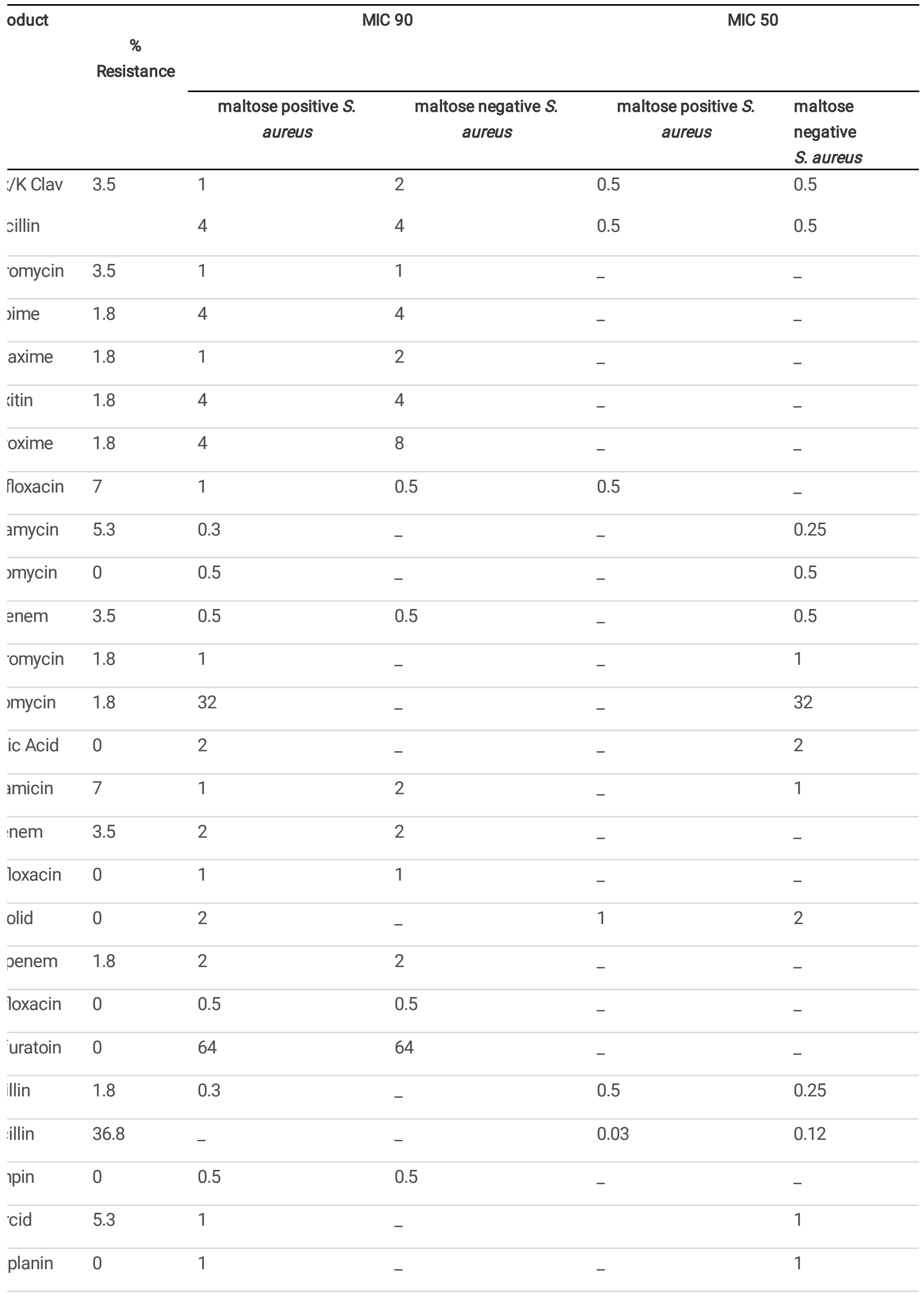




\begin{tabular}{llllll} 
zycline & 7 & 1 & 1 & 1 & - \\
\hline mycin & 3.5 & 1 & 1 & - & - \\
\hline th/Sulfa & 0 & 1 & 1 & - & 1 \\
\hline mmycin & 0 & 2 & - & 1 & 1 \\
\hline
\end{tabular}

Trimeth/Sulpha $=$ Trimethoprim $/$ Sulphamethoxazole; STA + = maltose positive $S$. aureus; STA - = maltose negative $S$. aureus; $\mathrm{n}=$ number of isolates

\section{Discussion}

Retrospective analysis (disk diffusion method) of maltose negative S. aureus

This study on the maltose negative $S$. aureus showed no significant differences of antimicrobial resistance between the provinces, and only a limited significant difference related to seasons and SCC categories (Tables $1 \& 2$ ). However, this comparison between the analysis of the effects of year, season, province and SCC categories of antimicrobial Resistance of maltose negative $S$. aureus shows that the use of the new definitions of Susceptible, Intermediate and Resistant [13] did indeed make a difference to the results (Tables $1 \& 2$ ). The logic behind the change of this grouping, was that in the past, Intermediate readings were grouped with Resistant readings to create more strictly defined categories.

The absence of differences between the nine provinces is easily understandable. With only 271 isolates and a very unequal distribution by provinces, 170, 56 and 27 isolates in Kwa Zulu Natal, Eastern Cape and Western Cape respectively all the other provinces showed less than 10 isolates. This discrepancy did not allow statistical analysis to show any differences between all provinces. The relationship of SCC category to antimicrobial resistance was in agreement with a study in Denmark [5], which also found high SCC to correspond with low antimicrobial resistance and vice versa. This could be due to the SCC being more of an indicator of irritation and severity of the infection rather than an indicator of antimicrobial resistance of the organism.

In contrast, the study on maltose positive $S$. aureus [16] showed that the lowest prevalence of antimicrobial resistance to the majority of the categories of antimicrobials that were tested, was present in KwaZulu-Natal during spring, except for cephalosporins which had the lowest levels of prevalence of bacterial resistance in Gauteng during winter [16]. Although, there were great differences in the numbers of herds and samples between the provinces, these differences were taken into account in the model, during the analysis.

One specific strain of maltose negative S. aureus ST 2992 was identified [17], originating in and found mostly in KwaZulu Natal, but also now present in all nine provinces of South Africa, albeit in small numbers. The antimicrobial resistance trends over time of this maltose negative $S$. aureus (Figures 1 to 6 ) were in agreement with those shown for the same antimicrobials with non-aureus staphylococci [30], but in contrast to the trends shown for the maltose positive S. aureus over time [15]. The study on the 
maltose positive $S$. aureus, showed a general increase in resistance over time except for the 20 well managed herds (part of the pro-active udder health programme) [15], which showed a decrease in resistance over time [15]. However, due to the general increase in antimicrobial resistance in recent years, there were some cases where there may not have been any effective products available. Then a product appropriate for an Intermediate response would have been used with increased exposure, which is why the Intermediate responses are now grouped with the Susceptible responses [13]. However, the trends of antimicrobial resistance over time of maltose negative $S$. aureus were evaluated with both the previous (Figures 1, 2 \& 3) and the more recent definitions have been similar for the products tested (Figures 4, 5 \& 6). The breakpoints are not just an indication of resistance. It takes into account concentrations at the level of the udder (i.e. its pharmacological resistance). In South Africa we have a limited variety of intramammary products available for use, mostly ampicillin, cloxacillin or combinations thereof. The products with available breakpoints for mastitis specifically, in the latest CLSI guidelines [8], are not available for use on the South African market. Thus, we used available CLSI veterinary breakpoints [8] and for the products on the MIC PM 32 panel with no available veterinary breakpoints, we used the CLSI human breakpoints [7], as explained and used in the publication by [38].

Minimum Inhibitory Concentrations $(\underline{\mathrm{MIC}})$ of maltose negative and maltose positive S. aureus

The MIC results (Table 3) confirmed the disk diffusion results (Tables $1 \& 2$ ) for maltose negative $S$. aureus for the products tested.

The distribution of the MIC test results of the antimicrobials tested are summarized in Table 3 for maltose positive and maltose negative $S$. aureus isolates respectively. Twelve maltose negative $S$. aureus isolates were resistant to oxacillin compared to only one maltose positive $S$. aureus. The same pattern was observed for erythromycin, nine maltose negative $S$. aureus isolates were resistant compared to one maltose positive $S$. aureus. The MICs of most products in the PM 32 panel differed between maltose negative and maltose positive $S$. aureus isolates (Table 3). In general, the resistance rates of the maltose positive $S$. aureus obtained in this study, corresponded well to those reported in other studies $[31 ; 40]$.

The MIC 50 represents the $M I C$ value at which $\geq 50 \%$ of the isolates in a test population are inhibited, and it is equivalent to the median MIC value. The MIC 90 represents the MIC value at which $\geq 90 \%$ of the isolates in the test population are inhibited [33]. The MIC breakpoints (chosen concentration $[\mu \mathrm{g} / \mathrm{ml}$ ] of an antimicrobial which defines whether a species of bacteria is Susceptible or Resistant to the antimicrobial) of certain antimicrobials were Susceptible for MIC 50 and MIC 90 for both the maltose negative and the maltose positive $S$. aureus, except for MIC 90 of maltose negative $S$. aureus (Table 3 ). The maltose negative $S$. aureus was more Resistant to the amoxicillin clavulanic acid combination (used in human medicine), ampicillin and cefuroxime at MIC 90, and for clindamycin at MIC 50 (Table 3). However, oxacillin was more Resistant for maltose positive $S$. aureus for MIC 90 and MIC 50 and clindamycin for MIC 90 (Table 3). Infrequently found resistance patterns were found in 17 of the 57 
maltose negative $S$. aureus isolates, which were resistant to vancomycin and one maltose positive and eight maltose negative $S$. aureus isolates which were resistant to oxacillin [10].

Overall in this study, there were more multidrug resistant maltose negative $S$. aureus than maltose positive $S$. aureus isolates and the same general interpretation applied for isolates resistant to two or more antimicrobials of varying combinations in general.

There have been many studies in both animal and human medicine that have identified multidrug resistant and pandrug resistant $S$. aureus isolates [11]. However, most of these studies were done on traditionally identified coagulase positive, maltose positive $S$. aureus. Although a coagulase positive, maltose negative $S$. aureus strain has been subsequently isolated from bovine mastitis [12], there appear to be no antimicrobial susceptibility profiles of this organism yet. The maltose negative $S$. aureus ST 2992 isolated from milk samples in South Africa was identified by MALDI-TOF MS and 16S r RNA sequence analysis [17].

Human nasal $S$. aureus colonization has previously been reported as a risk factor for pig farming [2] and $S$. aureus strains from pig farmers were found to be present in pigs and had not been found in nonfarmers [2; 39]. In the light of this research in pigs, it is possible that in a similar way of transmission of some strains of these resistant $S$. aureus (predominantly maltose negative strains) isolated from dairy cattle in South Africa could be from people. Previous studies done in KwaZulu Natal [34], have indicated anthroponosis of $S$. aureus in South Africa, with one of the strains identified as the same maltose negative $S$. aureus strain. Antimicrobials that are approved for human use only create a reserve of unique antimicrobials for humans. The use of antimicrobials that are approved for animal use only, such as the ionophores, should not create a risk to human health.

These maltose negative strains of $S$. aureus seem to have completely different antimicrobial resistance trends and severity of antimicrobial resistance, when compared to the traditionally identified maltose positive $S$. aureus and these infections thus need to be treated differently in practice.

Resistance to antimicrobial agents, such as doxycycline and trimethoprim-sulfamethoxazole is very uncommon in $S$. aureus. The reason for these uncommon resistance profiles of maltose negative $S$. aureus isolates, which have also shown to be resistant to antimicrobials that are only used in human medicine (e.g. carbapenems like imipenem and ertapenem), which had 10 resistant isolates each, remains questionable. These are antimicrobials which are not used at all in animal medicine.

Anthroponosis seems to be a strong possibility, because these isolates have been shown to be present on the skin of humans that come into close contact with dairy cattle. This would be similar to the findings of the studies with the dogs in Brazil [21] and pigs in Germany [2] and the Netherlands [40] respectively. Further studies need to be done in order to explore the origin of such resistant isolates of maltose negative $S$. aureus. Future work is also necessary to determine the resistance genes present in resistant maltose negative $S$. aureus strains. 
A similar study in dairy cattle in Tennessee also found that there was a variation of prevalence of antimicrobial resistance of $S$. aureus, with an increasing trend in tetracycline resistance [1]. This was also in accordance with the report which showed that the predominant antimicrobial groups used in animal health in South Africa from 2014 to 2015, were the growth promoters (animal-use-only antimicrobials) (62\%) followed by tetracyclines (17\%) and macrolides (11\%) [23]. Similarly this study showed five isolates resistant to tetracyclines and ten isolates resistant to macrolides. Only one of each of these isolates were maltose positive, whereas the rest were maltose negative $S$. aureus.

The use of antimicrobials in South Africa in 2015, has been stated to be 21149 standard units per 1000/population (IMS Health 2015) (Note: 1 standard unit is equivalent to 1 tablet, or injection), and this was significantly higher than most other countries in the world. Broad-spectrum penicillin usage in humans in South Africa was 1.3 to 3.3 times more than that used in other countries and 0.8 times that used in the United Kingdom or the USA [23] It is by no means clear if the high number of maltose negative $S$. aureus isolates resistant to penicillin and ampicillin might solely be attributed to the high antimicrobial usage.

\section{Antimicrobial resistance}

The antimicrobial resistance trends (Figures 1 to 6) and profiles (Table 3), allow for informed treatment choices to be made without the need to wait for specific antimicrobial sensitivity test results. However, the results of antimicrobial sensitivity tests (disk diffusion or MIC), are just an indication in vitro that the particular organism is likely to be killed by a particular antimicrobial. In the udder, the situation may be very different because the site of the infection may be very difficult to reach via very small arteries and lactiferous ducts and also due to udder pharmacodynamics (very few products are successful in a water and fat environment). As a result of this, the treatment success for mastitis in is not very high (27\%) [36] and can lead to the development of antimicrobial resistance by mastitis-causing organisms. In general, treatment success against $S$. aureus tends to be better in the dry period but still not ideal [3]. Therefore for mastitis control the focus should be on the prevention and monitoring through the pro-active udder health programme [28], rather than on treatment alone.

\section{Conclusion}

The antimicrobial resistance trends found were similar for both the previous (Intermediate responses grouped with Resistant responses) and the more recent definitions (Intermediate responses grouped with Susceptible responses) of analyses. These trends for ampicillin, cephalexin, cefalonium, cloxacillin, oxytetracycline and penicillin G peaked (at highest) in 2011 and for tylosin in 2013 and then decreased. These antimicrobial resistance trends over time, showed a closer comparison with analysis of similar data for non-aureus staphylococci than for the maltose positive $S$. aureus. Antimicrobial resistance trends over time also differed between maltose negative and maltose positive $S$. aureus. Antimicrobial resistance of maltose negative $S$. aureus showed no significant differences between provinces (using 
both the previous and also the more recent interpretation) and there were only limited differences between seasons for ampicillin, penicillin G, tylosin and cefalonium (using the more recent interpretation system). For cloxacillin and cefalonium specifically, high SCC corresponded with low antimicrobial resistance and were significantly different from low SCC which to corresponded with high antimicrobial resistance. However, using the latest definitions caused the significant effects of year, season, province and SCC category shown on antimicrobial resistance of tylosin, cloxacillin, oxy-tetracycline and cefalonium with the previous definitions, to disappear. The MIC results of antimicrobial resistance for maltose negative $S$. aureus confirmed the results of the disk diffusion method. The results of the MIC method also showed more resistance in general for maltose negative than for the maltose positive $S$. aureus isolates to most of the antimicrobials that were used. The MIC breakpoints were susceptible at MIC 50 and MIC 90 for both maltose negative and maltose positive $S$. aureus, with the exception of maltose negative $S$. aureus at MIC 90.

\section{Methods}

\section{Data collection and bacterial identification}

The milk laboratory of the Faculty of Veterinary Science (University of Pretoria) has been receiving samples from most of the commercial dairies in South Africa since 1999, as part of the pro-active udder health programme (routine testing of microbiology and cytology, every two to three months) [15]. Bacteriological analyses are done on a routine basis on all these samples. A total of 271 maltose negative $S$. aureus isolates were identified from a total of 117 dairy herds out of all the samples received from the total of 2000 dairy farms between 2009 and 2017[20]. The herd size of these 117 dairies varied from 67 to 1253 animals. These herds were located in all nine provinces of South Africa but with greatly varying numbers of the organism isolated from the different provinces, namely: Gauteng $(n=8)$, KwaZulu Natal $(n=170)$, Free State $(n=4)$, Eastern Cape $(n=56)$, Western Cape $(n=27)$, Northern Cape $(n=1)$, North West $(n=1)$, Limpopo (North) $(n=1)$ and Mpumalanga $(n=3)$. The numbers of maltose negative $S$. aureus isolated per farm varied from 1 to 19. The milk samples were collected in an aseptic manner according to a standard operating procedure [24]. These isolates were collected and cultured according to the method recommended by the National Mastitis Council [24] and somatic cell counts were performed using a Fossomatic 5000 and Fossomatic FC (Rhine Ruhr). Isolates to be tested for routine antimicrobial susceptibility were all selected from milk samples with a somatic cell count (SCC) (Fossomatic 5000 and Fossomatic FC, Rhine Ruhr) of more than 400000 cells/ml [25; 29], when applicable, in order to include cases of subclinical mastitis. This was the general rule for routine antimicrobial susceptibility testing. However, when a maltose negative $S$. aureus was isolated from a herd, antimicrobial sensitivity testing was done on that organism regardless of SCC [17]. Phenotypic differentiation of staphylococci was initially identified based on colony morphology, pigmentation, haemolysis, catalase, staphylase, maltose and potassium hydroxide tests that were used [29]. A positive maltose agar reaction confirmed $S$. aureus and a negative maltose reaction confirmed an organism potentially from the $S$. intermedius group [10; 35], on initial phenotypic identification [17]. However, the identification of these organisms was followed up using MALDI-TOF and $16 \mathrm{~S}$ sequencing. Both these methods confirmed that this was a maltose 
negative strain of $S$. aureus [17]. Further multi-locus sequence typing (MLST) and analysis of the MalA and MalR genes, revealed that this was maltose negative $S$. aureus ST 2992 with an abnormal stop codon on the MalA gene (GenBank accession number, MN531305)[17].

\section{Antimicrobial susceptibility testing}

\section{Disk diffusion method}

The disk diffusion method [4] was used to determine the antimicrobial susceptibility of the routine diagnostic samples that were used for the retrospective data analysis. The results were based on the diameter of the inhibition zones and were classified as Sensitive, Intermediate or Resistant (Intermediate grouped with Resistant) in accordance with the latest clinical breakpoints available at the time of the study, CLSI [7; 8]. The initial analysis was done using the previous definition of Susceptible, Intermediate and Resistant (Intermediate grouped with Resistant) [13]. These data were later reclassified according to the new definition of Susceptible, Intermediate and Resistant (Intermediate grouped with Susceptible) [13], and the results were compared. The decision to change this definition of interpretation was taken in June 2018, by the EUCAST steering committee [13].

Nine antimicrobials used for intramammary treatment (in lactation and dry cow therapy) that were available for use in South Africa were tested. These were the penicillins (ampicillin $10 \mu \mathrm{g}$, cloxacillin $5 \mu \mathrm{g}$, penicillin G $10 \mathrm{IU}$ ), cephalosporins (cephalexin $30 \mu \mathrm{g}$, cefuroxime $30 \mu \mathrm{g}$, cefoxitin $30 \mu \mathrm{g}$ ), lincosamides (clindamycin $10 \mu \mathrm{g}$ ), tetracyclines (oxy-tetracycline $30 \mu \mathrm{g}$ ) and macrolides (tylosin $30 \mu \mathrm{g}$ ). The lactating cow numbers of the herds in this study varied from approximately 30 (smallest herd) to 1700 cows, (largest herd) [20].

\section{MIC method}

In addition, MIC tests were performed on 57 coagulase positive, maltose negative $S$. aureus isolates (2012-2013 n=15; 2018-2019 n=42) and 57 maltose positive $S$. aureus isolates $(2012-2014 n=11$; 2017$2018 \mathrm{n}=46$ ), isolated from 38 dairy herds mainly from KwaZulu Natal and Eastern Cape provinces, but also with a few samples from Western Cape, Gauteng and Mpumalanga. The 57 maltose negative $S$. aureus isolates were the total number of these isolates collected during the time periods mentioned. For the maltose positive $S$. aureus isolates, the same number $(n=57)$ of isolates from the same farms, with similar corresponding SCC ranges and from similar time period to those of the maltose negative $S$. aureus samples were selected. Antimicrobial agents that were selected were based upon the availability of commercial intramammary infusion products or as representatives of their respective antimicrobial classes such as: ampicillin, oxacillin, erythromycin, penicillin and tetracycline. 
The MIC were determined by using the automated broth microdilution method (PM 32 panels and Microscan 40 Walkaway system, Beckman Coulter, California, USA) and the results were evaluated according to CLSI [7; 8].Staphylococcus aureus ATCC 25923 and S. pseudintermedius ATCC 49444 served as the reference strains for quality control purposes. The MIC data analysis used the LabPro software of the Microscan 40 Walkaway system, (Beckman Coulter, California, USA) in order to determine the MIC 90 and the MIC 50 was calculated manually.

\section{Statistical Analysis}

The retrospective data were originally analysed according to the previous definitions[13], as described above. However, after the introduction of the new definitions, these analyses were repeated using the recently introduced definitions [13], and the two sets of results were compared.

In order to analyse the different factors that could have an effect on the resistance of our isolates we used a two steps approach. Univariable analyses were first applied to explore the potential effects of these factors. Then univariate multivariable analyses were used to confirm these effects and explore interactions. Thus the Chi-square test was used to check for the existence of any effect of season or SCC category on the response variable, the resistance to the different antimicrobials. The SCC categories that were used were, low ( $<150 \times 10^{3}$ cells per $\mathrm{ml}$ milk), medium $\left(150 \times 10^{3}\right.$ to $400 \times 10^{3}$ cells per $\mathrm{ml}$ milk $)$ and high ( $>400 \times 10^{3}$ cells per $\mathrm{ml}$ milk). The season were defined as spring (September to November), summer (December to February), autumn (March to May) and winter (June to August). The nine province were kept and Fisher exact test was applied due to small numbers of isolates for 5 provinces in order to test this geographical effect.

These Chi-square and Fisher tests also allowed classification of the categories of each variable in order to introduce the one with the lowest level of resistance as the reference category in the following generalized mixed model (GLMM) analysis. Generalized linear mixed models are models taking into account non-independence among clustered observations. The variable defining the clusters is the random variable. As generalized models they allow non-linear relationship between the dependent variable (variable to be explained) and the parameters of the model [9]. In our univariate multivariable GLMM, the antimicrobial resistance of all $S$. aureus isolates was used as the dependent variable. As it is a binomial variable we used a logit link-function. Herd was introduced as the random variable. Then season, province and SCC category were introduced as the different categorical independent variables (parameters of the model). We added also the year as a numeric independent variable. Under the "goal of parsimony", a stepwise approach based on the smallest Akaike Information Criterion, was used to select the best model [6]. The likelihood ratio test was then applied to test the overall significance of the retained fixed effects. P-values lower than 0.05 were considered as statistically significant and p-values between 0.1 and 0.05 were considered as almost significant. The analysis were done separately for each antibiotic using the 'Ime4' and 'afex' packages of the R software (c) version 3.3.3. 


\section{Abbreviations}

AC: amox/k clav; AM: ampicillin; AZ: azithromycin; CE: cefepime; Class: number of antimicrobial classes that each isolate is resistant to; CLSI: clinical laboratory standards institute; CT: cefotaxime; CX: cefuroxime; CP: ciprofloxacin; DA: clindamycin, ET: ertapenem; E: erythromycin; FA: fusidic acid; FO: fosfomycin; FX: cefoxitin screen; G: gentamycin; GLMM: general linear mixed model; I: intermediate; IM: imipenem; LZ: linezolid; MDR: multidrug resistant; ME: meropenem; MIC: minimum inhibitory concentrations; MRSA: methicillin resistant Staphylococcus aureus; MU: muriprocin; N/A: not applicable; NS: not significant; $(n)$ : number of isolates; OX: oxacillin; PBP: penicillin binding protein; P: penicillin; R: resistance; RI: rifampin; SCC: somatic cell count; S; susceptible; SY: synercid; TEl: teicoplanin; TE: tetracycline; TO: tobramycin; T: total number of antimicrobial products resistant; VA: vancomycin

\section{Declarations}

\section{Ethics approval and consent to participate}

The study was a retrospective analysis approved by the University of Pretoria Ethics Committee (reference number V062/14). The laboratory that supplied the data provided written consent from owners for the data to be used for research purposes and this was approved by the ethics committee.

\section{Consent for publication}

The study does not involve human subjects and therefore no consent was required. However, the laboratory that supplied the study data provided consent for study results to be published.

\section{Availability of data and materials}

The datasets used and/or analysed during the current study are available from the corresponding author on reasonable request.

\section{Competing interests}

The authors declare that they have no competing interests.

\section{Funding}

This research was partly funded by the National Research Foundation. The funding body had no role in the design of the study and collection, analysis, and interpretation of data and in writing the manuscript. 


\section{Authors' contributions}

J.K. was the project leader, conceptualised and wrote the article and assisted in data collection and performed MIC testing. E.M.C.E. performed all the statistical analysis and

assisted in writing up the portions related to the analysis. E.F.D., V.N. and I.-M.P. assisted in conceptualising and writing the article as well as reviewing the manuscript. E.F.D. also assisted with language editing. I.-M.P. assisted with all udder health-related portions and V.N. assisted with the pharmacology and MIC -related aspects.

\section{Acknowledgements}

The authors thank the milk producers for allowing them to use the data and the samples obtained on their farms. Thanks are also due to the staff of the Milk Laboratory, Department of Production Animal Studies, Faculty of Veterinary Science, University of Pretoria, at Onderstepoort, for the laboratory analyses: Mrs J.C. Watermeyer, Miss R. Badenhorst, Mrs E.F. Konaite, Mr K.S. Malekane, Miss O.P. Nchako and Miss O.I. Memma. The authors also thank Prof Nontombi Mbelle and Mrs Dina Pombo of Tshwane Academic Division, Microbiology, NHLS for the use of their facilities and Mr Thomas M. Rafundisani of Beckman Coulter for his help with the Microscan testing and analysis.

\section{References}

[1] Abdi RD, Gillespie BE, Vaughn J, Merrill C, Headrick SI, Ensermu DB, D'Souza DH, Agga GE, Almieda RA, Olivier SP, Kerro Dego O. Antimicrobial resistance of Staphylococcus aureus isolates from dairy cows and genetic diversity of resistant isolates. Foodborne Pathog. Dis. 2018;15(7):449-458. doi:

$10.1089 /$ fpd.2017.2362

[2] Aubry-Damon H, Grenet K, Sall-Ndiaye P, Che D, Cordeiro E, Bougnoux M, Rigaud E, Le Strat $Y$, Lemanissier V, Armand-Lefe` vre L, Delzescaux D, Desenclos J, Lie'nard M, Andremont A. Antimicrobial resistance in commensal flora of pig farmers. Emerg. Infect. Dis. 2004;10:873-879.

[3] Barkema HW, Schukken YH, Zadoks RN. Invited Review: The role of cow, pathogen, and treatment regimen in the therapeutic success of bovine Staphylococcus aureus J. Dairy Sci. 2006;89(6):1877-1895.

[4] Bauer AW, Kirby WM, Sherris JC, Turck M. Kirby Bauer method antimicrobial susceptibility testing by a standardized single disk method. J. Clin. Pathol. 1966;45(4):493496. https://doi.org/10/1093/ajcp/45.4 ts.493

[5] Bennedsgaard TW, Thansborg SM, Aarestrup F.M, Enevoldsen C, Vaarst M, Christoffersen AB. Resistance to penicillin of Staphylococcus aureus isolates from cows with high somatic cell counts in 
organic and conventional dairy herds in Denmark. Acta Vet. Scand. 2006;48:24. https://doi.org/10.1186/1751-0147-48-24.

[6] Burnham KP, Anderson DR. Model selection and multi-model inference: a practical informationtheoretic approach. 2nd ed. New York: Springer; 2002. ISBN 0-387-95364-7

[7] Clinical and Laboratory Standards. Clinical and Laboratory Standards Institute. Performance standard for antimicrobial susceptibility testing. Twenty-fifth information supplement M100-S25. Wayne: Clinical and Laboratory Standards Institute; 2015.

[8] Clinical and Laboratory Standards. Clinical and Laboratory Standards Institute. Performance standards for antimicrobial disk and dilution susceptibility tests for bacteria isolated from animals; approved standard third edition. CLSI document VET01-A4; 2013.

[9] Dohoo R, Ducrot C, Fourichon C, Donald A, Hurnik D. An overview of techniques for dealing with large numbers of independent variables in epidemiological studies. Prev. Vet. Med. 1997;29(3);221-239. https://doi.org/10.1016/S0167-5877(96)01074-4.

[10] Hajek V. Staphylococcus intermedius, a new species isolated from animals. Int. J. Syst. Bacteriol. 1976;26:401-408.

[11] Haran KP, Godden SM, Boxrud D, Jawahir S, Bender JB, Sreevatsan S. Prevalence and characterization of Staphylococcus aureus, including methicillin-resistant Staphylococcus aureus, isolated from bulk tank milk from Minnesota dairy farms. J. Clin. Microbiol. 2012;50(3):688695. doi:1128/JCM.05214-11.

[12] Johler S, Moser M, Engl C, Tasara T, Corti S, Chen J, Stephan RA, Coagulase- and a-glucosidasenegative variant of Staphylococcus aureus: a challenge for routine microbiological diagnostics. J. Clin. Microbiol. 2012;5(50):1827-1828. doi:10.1128/JCM.06345-11.

[13] Kahlmeter G and the EUCAST Steering Committee. Redefining susceptibility testing categories S, I and R. European Committee on Antimicrobial Susceptibility Testing (EUCAST), European Society of Clinical Microbiology and Infectious Diseases. 2019. http://www.eucast.org. Accessed 28 March 2020.

[14] Karzis J. Antibiotic resistance of coagulase positive Staphylococci isolated from milk of South African dairy herds. PhD Thesis, University of Pretoria, 2020.

[15] Karzis J, Petzer IM, Donkin EF, Naidoo V. Proactive udder health management in South Africa and antimicrobial resistance monitoring of Staphylococcus aureus in dairy herds from 2001 to 2010. JSAVA 2018;89(0):a1490. doi.10.4102/jsava v89i0-1490.

[16] Karzis J, Petzer IM, Donkin EF, Naidoo V, Etter EMC. Climatic and regional antibiotic resistance patterns of Staphylococcus aureus isolated from milk samples of dairy herds in South Africa between 2000 and 2010. Onderstepoort J. Vet. Res. 2019;86(1):a1674. https://doi.org/10.4102/ojvr.v86i1.1674. 
[17] Karzis J, Petzer IM, Donkin EF, Naidoo V, Labuschagne C. Challenging the conventional identification of coagulase positive staphylococci through the use of molecular techniques. J. Dairy Sci. 2020;manuscript no.2019-17901:in Press.

[18] Klevens RM, Morrison MA, Nadle J, Petit S, Gershman K, Ray S, Harrison LH, Lynfield R, Dumyati G, Townes JM, Craig AS, Zell ER, Fosheim GE, McDougal LK, Carey RB, Fridkin SK. Investigators ABCs AM: Invasive methicillin-resistant Staphylococcus aureus infections in the United States. J. Am. Med. Assoc. 2007;298:1763-1771.

[19] Kwon N, Park K, Jung W, Youn H, Lee Y, Kim S, Bae W, Lim J, Kim J, Kim J, Hong S, Park Y. Characteristics of methicillin resistant Staphylococcus aureus isolated from chicken meat and hospitalized dogs in Korea and their epidemiological relatedness. Vet. Microbiol. 2006;117, 304-312.

[20] Lactodata. Milk SA. 2013. http://milksa.co.za/category/all-reports/industry-information. Accessed 7 June 2017.

[21] Machado AB, Machado MFR, Picoli SU. An investigation of methicillin-resistant Staphylococcus pseudintermedius (MRSP) in domestic and shelter dogs in Montenegro (RS-Brazil). Revista Brasileira de Saúde e Produção Animal 2017 ;18(4):542-548. doi.org/10.1590/s1519-99402017000400005.

[22] Magiorakos AP, Srinivasan A, Carey RB, Carmeli Y, Falagas ME, Giske CG, Harbarth S, Hindler JF, Kahlmeter G, Olsson-Liljequist B, Paterson DL, Rice LB, Stelling J, Struelens MJ, Vatopoulos A, Weber JT, Monnet DL. Multidrug-resistant, extensively drug resistant and pandrug-resistant bacteria: and international expert proposal for interim standard definitions for acquired resistance. Clin. Microboil. Infect. 2012;18(3):268-281. doi: 10.1111/j.1469-0691.2011.03570.x.

[23] National Department of Health. Surveillance resistance and consumption of antibiotics in South Africa. 2018.

[24] National Mastitis Council. Microbiological procedures for the diagnosis of bovine udder infection and determination of milk quality - Fourth edition. 2004. http://www.nmconline.org. Accessed 1 August 2017.

[25] Nickerson SC, Owens WE, Boddie RL. Symposium: Mastitis in dairy heifers: initial studies on prevalence and control. J. Dairy Sci. 1995;78:1607-1618.

[26] Piessens V ${ }^{1}$, Van Coillie E, Verbist B, Supré K, Braem G, Van Nuffel A, De Vuyst L, Heyndrickx M, De Vliegher S. Distribution of coagulase-negative Staphylococcus apecies from milk and environment of dairy cows differs between herds. J. Dairy Sci. 2011;94(6):2933-2944. doi: 10.3168/jds.2010-3956.

[27] Petzer IM, Karzis J, Watermeyer JC, van der Schans TJ, Badenhorst R. Trends in udder health and emerging mastitogenic pathogens in South African dairy herds. JSAVA 2009;80(1):17-22. 
[28] Petzer IM, Karzis J, Donkin EF, Webb EC. A pathogen-specific approach towards udder health management in dairy herds: Using culture and somatic cell counts from routine herd investigations. Onderstepoort J. Vet. Res. 2016;83(1):12. doi: https://doi.org/10.4102/ojvr.v83i1.1146.

[29 Petzer, IM, Karzis J, Donkin EF, Webb EC, Etter EMC. Somatic cell count thresholds in composite and quarter milk samples as indicator of bovine intramammary infection status. Onderstepoort J. Vet. Res. 2017;84(1):a1269. https://doi.org/10.4102/ojvr.v84i1.1269

[30] Petzer IM, Karzis J. Virulence, antibiotic resistance and diagnostics of CNS isolated from milk of SA dairy cows. RuVasa Congress, Umhlanga Rocks, South Africa 2019.

[31] Salmon SA, Watts JL, Aarestrup FM, Pankey JW, Yancey RJ Jr. Minimum inhibitory concentrations for selected antimicrobial agents against organisms isolated from the mammary glands of dairy heifers in New Zealand and Denmark. J. Dairy Sci. 1998;81(2):570-578.

[32] Sasaki T, Kikuchi K, Tanaka Y, Takahashi N, Kamata S, Hiramatsu K, Reclassification of phenotypically-identified Staphylococcus intermedius J. Clin. Microbiol. 2007;45:2770-2778.

[33] Schmidt $\mathrm{LH}$. The $\mathrm{MIC}_{50} / \mathrm{MIC}_{90}$ : assessments of in vitro activities of antimicrobial agents that facilitate comparative agent-agent and agent-species susceptibility comparisons. Newslett. 1987;4(1):1-8.

[34] Schmidt T, Kock MM, Ehlers MM. Diversity and antimicrobial susceptibility profiling of staphylococci isolated from bovine mastitis cases and close human contacts. J. Dairy Sci. 2015;98:6256-6269. http://dx.doi.org/10.3168/jds.2015-9715.

[35] Sol J, Sampimon OC, Snoep JJ, Schukken YH. Factors associated with bacteriological cure during lactation after therapy for subclinical mastitis caused by Staphylococcus aureus. J. Dairy Sci. 1997;80(11):2803-08.

[36] Swinkels JM, Cox P, Schukken YH, Lam TJ. Efficacy of extended cefquinome treatment of clinical Staphylococcus aureus J. Dairy Sci. 2013;96(8):4983-92. doi: 10.3168/jds.2012-6197.

[37] Tenhagen BA, Hansen I, Reinecke A, Heuwieser W. Prevalence of pathogens in milk samples of dairy cows with clinical mastitis and in heifers at first parturition. J. Dairy Res. 2009;76(2):179-187.

[38] Toutain PL, Bousquet-Mélou A, Damborg P, Ferran AA, Mevius D, Pelligand L, Veldman KT, Lees P. En route towards European clinical breakpoints for veterinary antimicrobial susceptibility testing: A position paper explaining the VetCAST approach. Microbiol. 2017;;8:2344.

https://doi.org/10.3389/fmicb.2017.02344.

[39] Voss A, Loeffen F, Bakker J, Klaassen C, Wulf M. Methicillin resistant Staphylococcus aureus in pig farming. Emerg. Infect. Dis. 2005;11:1965-1966. 
[40] Wallmann J, Kaspar H, Kroker R. The prevalence of antimicrobial susceptibility of veterinary pathogens isolated from cattle and pigs: national antibiotic resistance monitoring 2002/2003 of the BVL. Münch. Tierärztl. 2004;117(11-12):480-492.

[41] Zadoks R, Fitzpatrick J. Changing trends in mastitis. Vet. J. 2009;62 Suppl 4:S59-70. doi:10.1186/2046-0481-62-S4-S59.

\section{Figures}

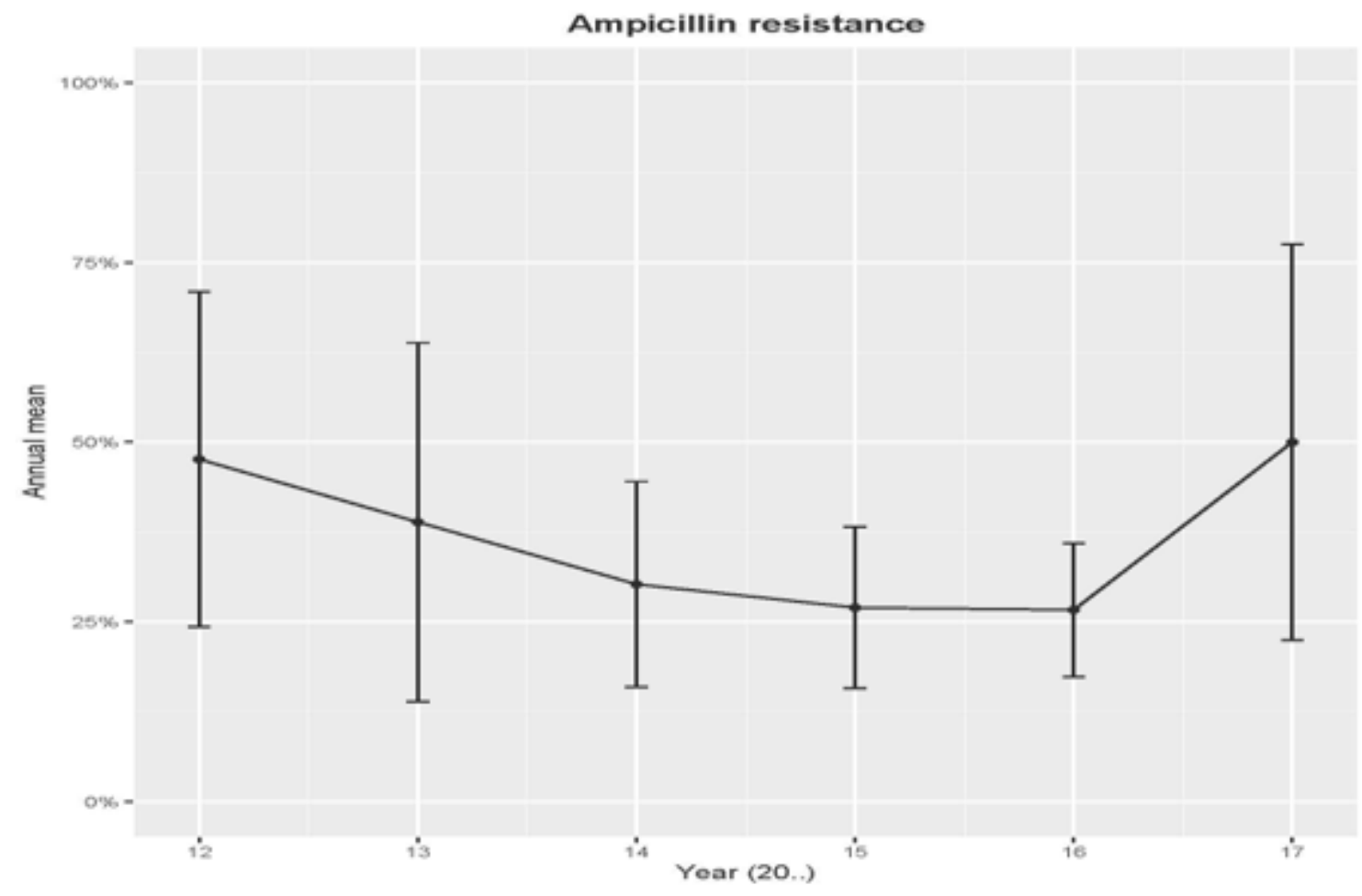

\section{Figure 1}

Trends of antimicrobial resistance to ampicillin over time of maltose negative S. aureus. Resistance mean is the proportion of isolates per year; this figure used the disk diffusion, retrospective data, according to CLSI [7; 8], with Intermediate responses grouped with Resistant responses (the previous definitions) [13]. 


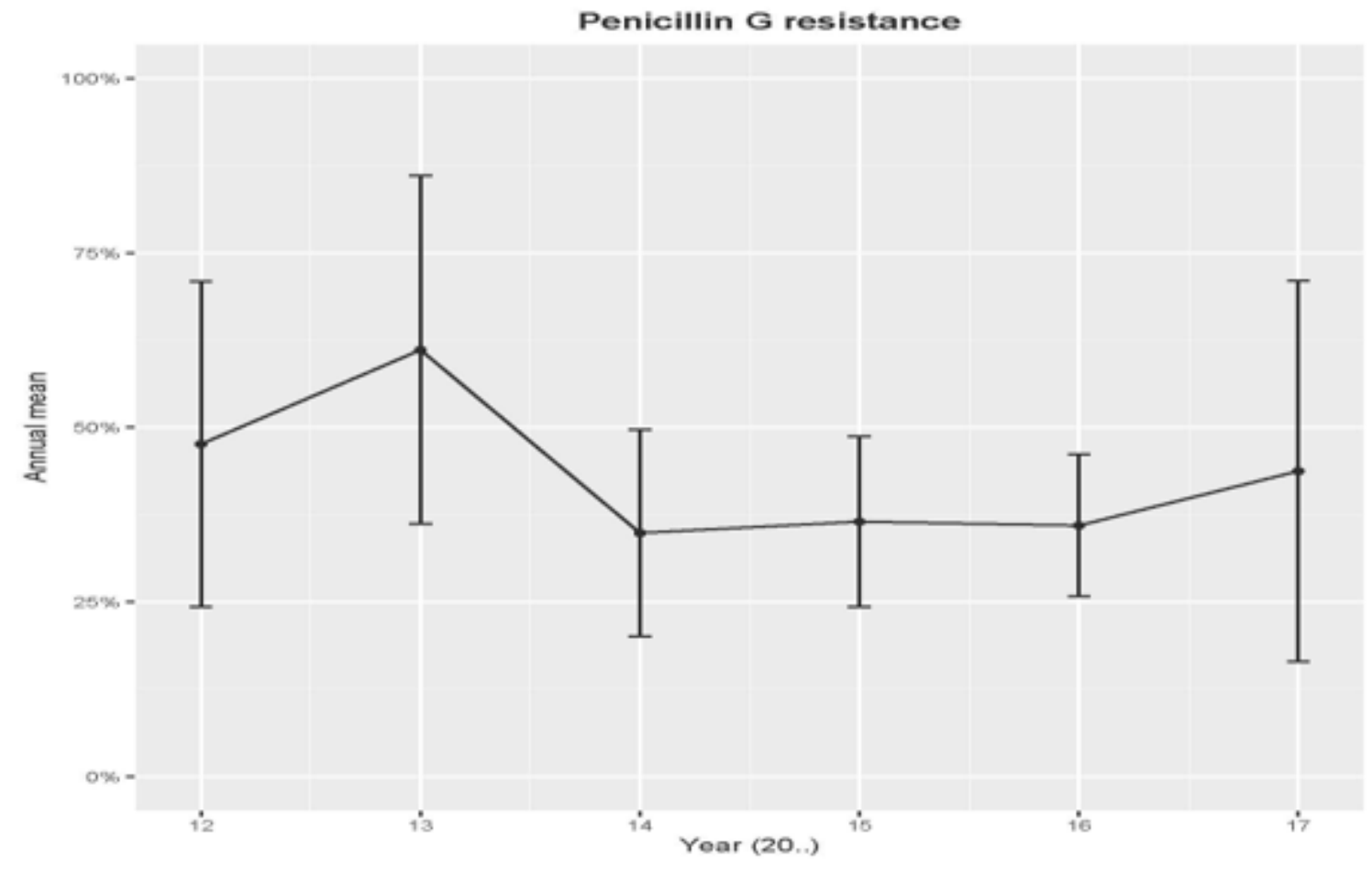

Figure 2

Trends of antimicrobial resistance over time to penicillin $\mathrm{G}$ of maltose negative $\mathrm{S}$. aureus. Resistance mean is the proportion of isolates per year; this figure used the disk diffusion, retrospective data, according to CLSI [7; 8], with Intermediate responses grouped with Resistant responses (the previous definitions) [13].

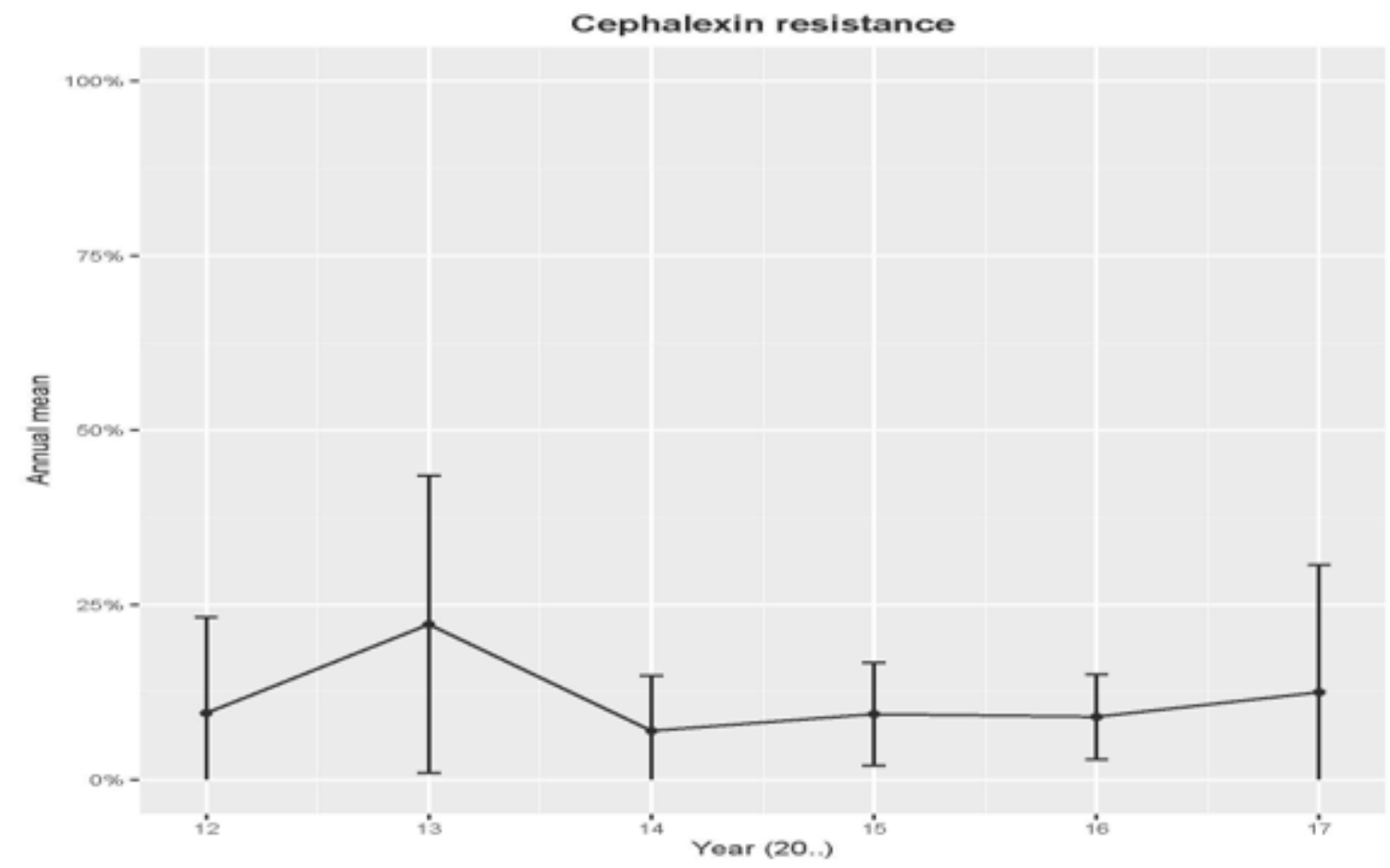




\section{Figure 3}

Trends of antimicrobial resistance to cephalexin over time of maltose negative S. aureus. Resistance mean is the proportion of isolates per year; this figure used the disk diffusion, retrospective data, according to CLSI [7; 8], with Intermediate responses grouped with Resistant responses (the previous definitions)[13].

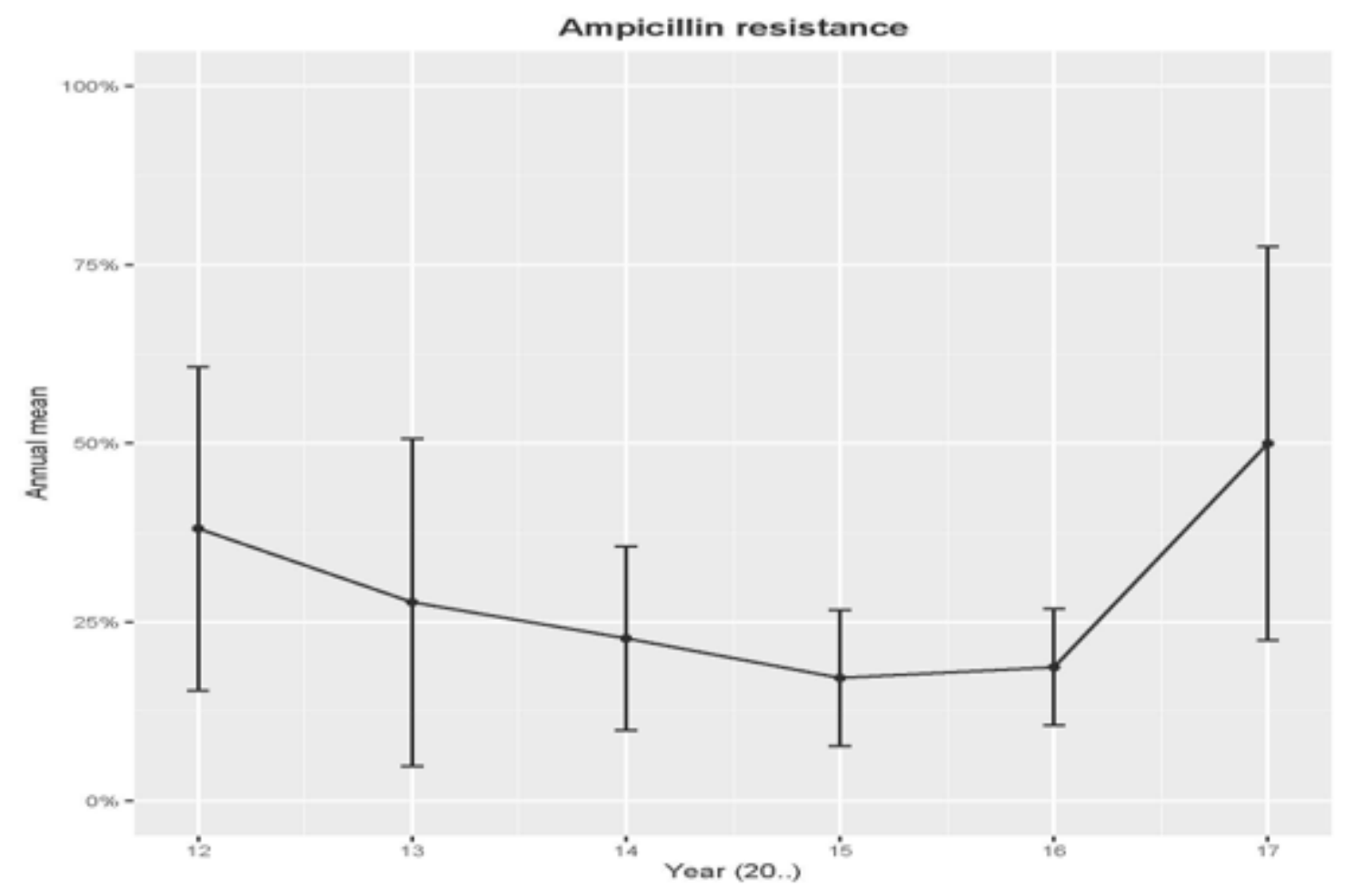

\section{Figure 4}

Trends of antimicrobial resistance to ampicillin over time of maltose negative S. aureus. Resistance mean is the proportion of isolates per year; this figure used the disk diffusion, retrospective data, according to CLSI [7; 8], with Intermediate responses grouped with Susceptible responses (the more recent system definitions) [13]. 


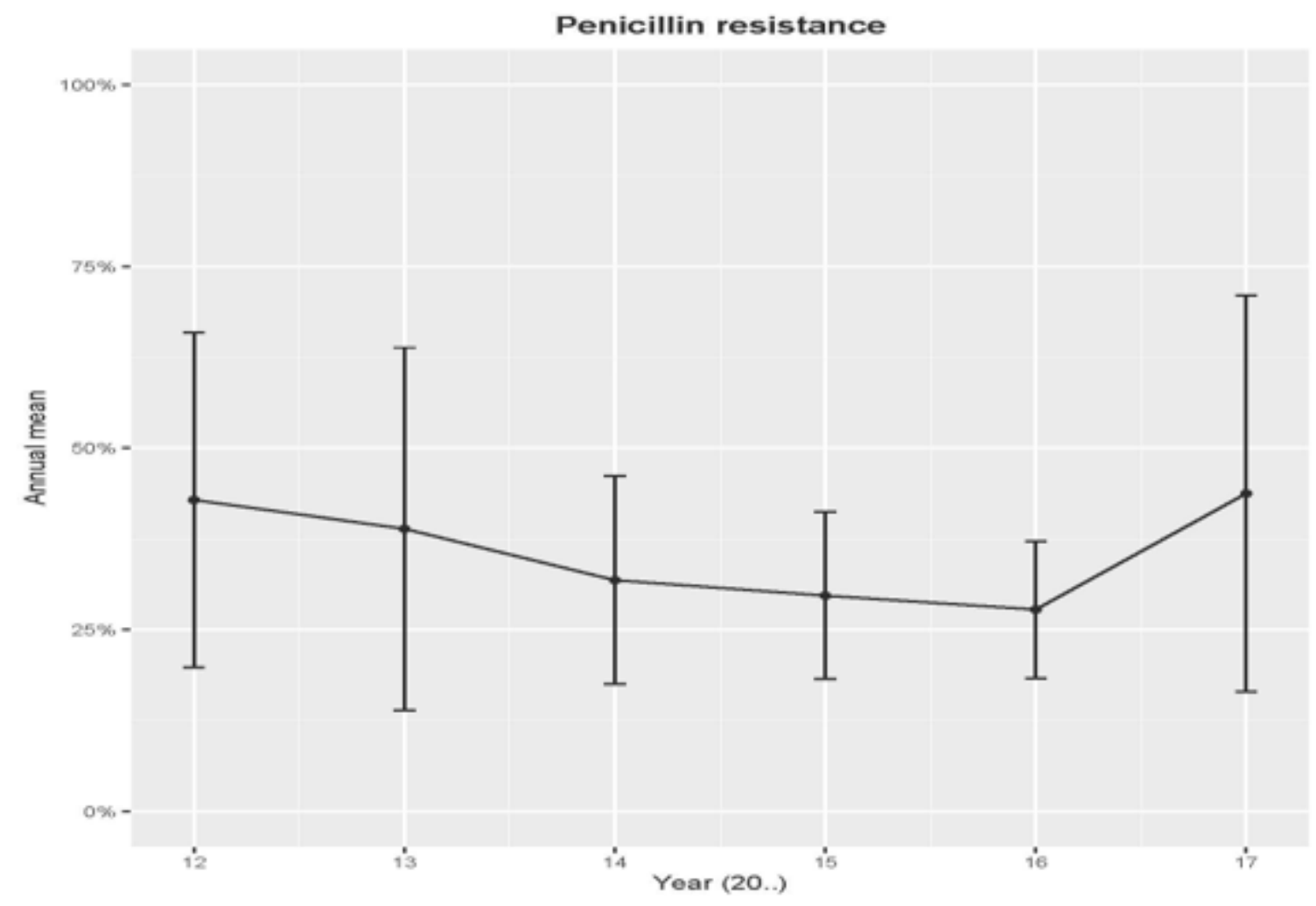

Figure 5

Trends of antimicrobial resistance to penicillin G over time of maltose negative S. aureus Resistance mean is the proportion of isolates per year; this figure used the disk diffusion, retrospective data, according to CLSI [7; 8], with Intermediate responses grouped with Susceptible responses (the more recent definitions) [13]. 


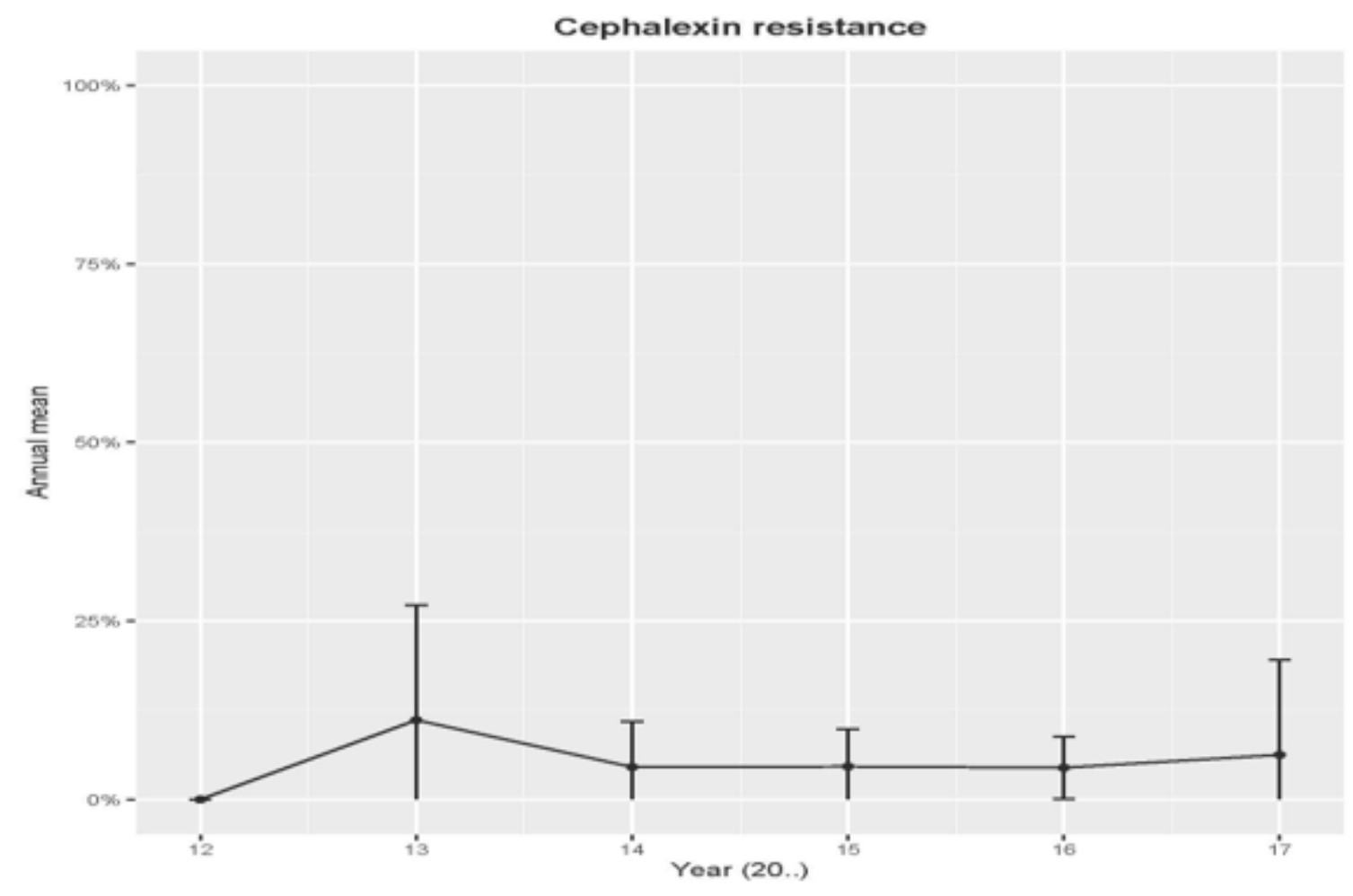

Figure 6

Trends of antimicrobial resistance to cephalexin over time of maltose negative S. aureus. Resistance mean is the proportion of isolates per year; this figure used the disk diffusion, retrospective data, according to CLSI [7; 8], with Intermediate responses grouped with Susceptible responses (the more recent definitions) [13].

\section{Supplementary Files}

This is a list of supplementary files associated with this preprint. Click to download.

- Supplementarymaterial.docx 